\title{
Economic burden of diagnosed pertussis among individuals with asthma or chronic obstructive pulmonary disease in the USA: an analysis of administrative claims
}

\author{
P. O. BUCK ${ }^{1 *}$, J. L. MEYERS ${ }^{2}$, L.-D. GORDON ${ }^{1}$, R. PARIKH ${ }^{2}$, S. K. KUROSKY ${ }^{2}$ \\ AND K. L. DAVIS ${ }^{2}$ \\ ${ }^{1}$ GSK, 5 Crescent Drive, Philadelphia, PA, 19112, USA \\ ${ }^{2}$ RTI Health Solutions, Research Triangle Park, 3040 Cornwallis Road, Post Office Box 12194, NC, 27709, USA
}

Received 5 January 2017; Final revision 10 March 2017; Accepted 29 March 2017;

first published online 2 May 2017

\section{SUMMARY}

Individuals with chronic respiratory conditions may be at increased risk for pertussis. We conducted a retrospective administrative claims analysis to examine the incidence and economic burden of diagnosed pertussis among adolescents and adults in the USA with chronic obstructive pulmonary disease (COPD) or asthma. Patients aged $\geqslant 11$ years with diagnosed pertussis and pre-existing COPD $(n=343)$ or asthma $(n=1041)$ were matched 1:1 to patients with diagnosed pertussis but without COPD or asthma. Differences in all-cause costs ('excess' costs) during the 45-day and 3-month and 6-month periods before and after the pertussis index date were calculated; adjusted excess costs were estimated via multivariate regressions. The incidence of diagnosed pertussis was higher among patients with COPD or asthma than among matched patients. Compared with matched patients, patients with pertussis and pre-existing COPD or asthma accrued greater all-cause adjusted costs across study periods (\$3694 and \$1193 more, respectively, in the 45-day period; $\$ 4173$ and $\$ 1301$ more in the 3-month period; and $\$ 6154$ and $\$ 1639$ more in the 6-month period; all $P<0 \cdot 0001$ ). Patients with pre-existing COPD or asthma experience an increased economic burden after diagnosed pertussis and may especially benefit from targeted tetanus, diphtheria, and acellular pertussis vaccination strategies.

Key words: Asthma, chronic obstructive pulmonary disease, economic burden, pertussis, retrospective database analysis.

\section{INTRODUCTION}

Pertussis is a highly communicable respiratory illness caused by the Bordetella pertussis bacterium, characterized by a prolonged paroxysmal cough and inspiratory whoop. After the introduction of the pertussis vaccine, the incidence of pertussis in the USA dropped substantially (from 150 cases per 100000 persons between 1940 and 1945 to a low of approximately 1 per 100000

\footnotetext{
* Author for correspondence: P. O. Buck, GSK, 5 Crescent Drive, Philadelphia, PA, 19112, USA.

(Email: philip.o.buck@gsk.com)
}

persons in 1980-1990) [1]. However, recent surveillance statistics indicate a resurgence of pertussis in communities nationwide. In 2012, more than 48000 cases of pertussis (incidence: $15 \cdot 4$ per 100000 persons) were reported to the Centers for Disease Control and Prevention (CDC), an increase from 2011 (incidence: $6 \cdot 1$ per 100000 population) [2]. Infants younger than 12 months of age had the highest incidence (126.7 cases per 100000 persons), followed by adolescents aged $11-14$ years $(59 \cdot 2$ per 100000$)$. Despite the high incidence of pertussis in infants and children, more than half of all reported cases in 2012 occurred in persons aged 11 years and older [3]. 
Research has shown that the clinical presentation of pertussis in adolescents and adults is characterized by symptoms including paroxysm, whoop, posttussive apnea, and posttussive vomiting [4]. Among adolescents and adults, complications such as pneumonia, fainting, urinary incontinence, and hospitalization have been shown to increase with age [5]. Furthermore, costs associated with pertussis in adults are substantial, with previous studies estimating costs per pertussis episode among patients aged 50 years and older in the USA to be between $\$ 1800$ and $\$ 14$ 500, depending on the treatment setting [6].

As pertussis is an infection of the respiratory tract, patients with chronic respiratory conditions such as asthma or chronic obstructive pulmonary disease (COPD) may be at increased risk for pertussis. There is some evidence showing that patients with asthma have a higher incidence of pertussis than patients without asthma $[5,7,8]$. In addition, a small case-control study $(N=90)$ found that anti-pertussis toxin immunoglobulin $G$ seropositivity was significantly higher in patients with COPD than in control patients [9]; however, the burden of pertussis in patients with COPD requires further characterization. To bridge this research gap and provide important information on the burden of pertussis in potential high-risk groups, the objective of this study was to generate US-specific data on the incidence and economic burden of diagnosed pertussis among adolescents and adults with a pre-existing diagnosis of asthma or COPD.

\section{METHODS}

\section{Study design and data source}

A retrospective cohort study using US administrative claims (i.e., inpatient, outpatient, and pharmacy claims) was conducted. The data sources were the MarketScan Commercial Claims and Encounters and Medicare Supplemental and Coordination of Benefits (1/2006-6/2014) and Medicaid Multi-State (1/2007-12/2013) databases. The authors' data access was restricted to the HIPAA (Health Insurance Portability and Accountability Act)-compliant de-identified data.

\section{Patient selection criteria and study cohorts}

Patients were selected for the study cohorts based on standard claims-based algorithms. Specifically, patients were identified for inclusion in the analysis if they had a primary or secondary diagnosis of pertussis (defined by International Classification of Diseases, Ninth Revision, Clinical Modification (ICD-9-CM) codes 033.0x, 033.9x, and 484.3x [6]). To allow for inclusion of health care resources related to the workup of the pertussis diagnosis (e.g., initial office visits and laboratory tests), the index date was defined as the date of the first observed pertussis diagnosis minus 15 days. Patients were required to have at least 6 months of continuous enrollment before and after the index date and to be aged 11 years or older.

The pre-existing COPD and pertussis (COPD + PERT) cohort included patients with at least two claims (i.e., inpatient, emergency department, or outpatient) spaced at least 14 days apart with a COPD diagnosis (ICD-9-CM codes 491.xx, 492.xx, or 496. $\mathrm{xx}$ ) and at least one COPD diagnosis in the 6 months before the index date. A previous study required multiple COPD claims to define exposure status [10], and the specificity and sensitivity of multiple claims with COPD diagnoses have been estimated at approximately $80 \%[11,12]$. The pre-existing asthma and pertussis (ASTHMA + PERT) cohort included patients with one inpatient or emergency department visit with a diagnosis of asthma or two outpatient visits with a diagnosis of asthma and at least one prescription for an asthma medication, with the first observed asthma diagnosis occurring in the 6 months before the index date. A variety of algorithms have been used to identify patients with asthma in health care claims data (e.g., $[13,14])$; the algorithm used in this analysis was based on common themes of identifying patients with encounters for severe asthmatic events (inpatient or emergency department visits) or encounters for managing asthma (outpatient visits plus medication). All qualified patients identified from the database and meeting the study eligibility criteria were included in the analysis. To control for differences in underlying demographic and clinical characteristics, patients with pre-existing COPD or asthma and pertussis were matched 1:1 to patients with pertussis and no pre-existing COPD or asthma using direct covariate matching. The covariates included were patient age, sex, insurance payer, categorical Charlson Comorbidity Index (CCI) score excluding COPD (i.e., $0,1,2$, and $\geqslant 3$ ), year of pertussis diagnosis, and costs in the 6 months pre-index date by quartile.

\section{Study measures}

All-cause health care costs were calculated for three time periods: 45 days pre-index date and 45 days post- 
index date; 3 months pre-index date and 3 months post-index date; and 6 months pre-index date and 6 months post-index date. Pertussis-related health care costs were calculated for the post-index date time periods only. All-cause health care costs included all medical and pharmacy costs, regardless of the corresponding diagnoses or prescriptions. Pertussis-related health care costs included inpatient or emergency department visits with a primary diagnosis of pertussis; outpatient visits with a primary or secondary diagnosis of pertussis; and pharmacy claims for azithromycin, clarithromycin, erythromycin, or trimethoprim-sulfamethoxazole. Cost analyses were conducted from the total burden of disease perspective and included all payments made by the insurance provider, third parties (e.g., Medicare), and the patient. Cost data were adjusted to 2014 US dollars using the medical care component of the US Consumer Price Index [15].

\section{Data analyses}

The incidence of diagnosed pertussis among patients with pre-existing COPD and among patients with preexisting asthma, as well as among patients without pre-existing conditions, was calculated. Person-time (reported as person-years) accumulated during the follow-up period served as the denominator in assessing the incidence rate. The follow-up period started on the enrollment date of patients without pre-existing asthma or COPD or the exposure index date among patients with pre-existing asthma or pre-existing COPD and ended with the pertussis index date among patients with pertussis, or the end of enrollment or end of the study period (whichever came first) among patients who were not diagnosed with pertussis. Estimation of $95 \%$ confidence intervals (CIs) was based on the Poisson distribution $[16,17]$. The incidence of diagnosed pertussis was calculated for patients with and without pre-existing asthma or COPD and was stratified by age. In addition, the relative risk of diagnosed pertussis among patients with each pre-existing condition compared with those without pre-existing conditions was computed and stratified by age.

Regression models were estimated to determine the adjusted excess costs during the 45-day and 3- and 6-month periods after the study index date. Adjusted health care costs were reported for each post-index date time period using a generalized estimating equation model with a log-link for the mean and a $\gamma$ distribution for the residuals. The covariates included in the model were pre-existing COPD or asthma, sex, geographic region, health plan type, payer type, CCI score, year of diagnosis, age, and baseline costs. Missing values for certain variables (e.g., region) were treated as a separate category but were not excluded from the analysis. From the model estimations, predicted costs were generated and reported for the COPD + PERT cohort, the ASTHMA + PERT cohort, and the respective matched cohorts. Adjusted excess health care costs were reported as the adjusted costs for the COPD + PERT cohort or the ASTHMA + PERT cohort minus the adjusted costs for the respective matched cohort.

\section{RESULTS}

\section{Incidence of diagnosed pertussis}

Table 1 presents the incidence of diagnosed pertussis in the MarketScan database population. The overall incidence of pertussis among patients with pre-existing COPD was $0 \cdot 176(95 \%$ CI $0 \cdot 166-0 \cdot 185)$ per 1000 person-years (relative risk, 2.533 (95\% CI $2 \cdot 396$ $2.678)$ vs. patients without asthma or COPD). Among patients with pre-existing COPD, the relative risk of pertussis was highest among patients aged 19-64 years (relative risk, 3.588 (95\% CI 3.3533.840)). The overall incidence of pertussis among patients with pre-existing asthma was $0.274(95 \%$ CI $0 \cdot 265-0 \cdot 285$ ) per 1000 person-years (relative risk, $3.959(95 \%$ CI $3.808-4 \cdot 115)$ vs. patients without asthma or COPD). Among patients with pre-existing asthma, the relative risk of pertussis was also highest among patients aged 19-64 years (relative risk 4.060 (95\% CI 3·861-4·269)).

\section{Sample characteristics}

A total of 441 patients who qualified for the cohort with pre-existing COPD and pertussis (i.e., the COPD + PERT cohort) and 1157 patients who qualified for cohort with pre-existing asthma and pertussis (i.e., the ASTHMA + PERT cohort) were identified. Matching resulted in 343 patients in the COPD + PERT cohort and 1041 patients in the ASTHMA + PERT cohort. Table 2 presents the sample characteristics.

The mean (standard deviation (s.D.)) age of the COPD + PERT cohort was $53 \cdot 2(18 \cdot 4)$ years, and approximately two-thirds of this cohort was female. 
Table 1. Incidence of diagnosed pertussis among adolescents and adults with pre-existing COPD or asthma

\begin{tabular}{|c|c|c|c|c|}
\hline Cohort & $N$ & $\begin{array}{l}\text { Sum of } \\
\text { follow-up } \\
\text { time (years) }\end{array}$ & $\begin{array}{l}\text { Incidence per } \\
1000 \text { person-years } \\
(95 \% \mathrm{CI})\end{array}$ & $\begin{array}{l}\text { Relative risk } v s . \text { patients } \\
\text { with no pre-existing } \\
\text { Asthma or COPD }(95 \% \mathrm{CI})\end{array}$ \\
\hline \multicolumn{5}{|l|}{ Overall } \\
\hline $\begin{array}{l}\text { Patients with pre-existing COPD and } \\
\text { pertussis }\end{array}$ & 1313 & 1940 & $0 \cdot 176(0 \cdot 166-0 \cdot 185)$ & $2 \cdot 533(2 \cdot 396-2 \cdot 678)$ \\
\hline $\begin{array}{l}\text { Patients with pre-existing COPD and no } \\
\text { pertussis }\end{array}$ & 2681930 & 7476119 & & \\
\hline $\begin{array}{l}\text { Patients with pre-existing asthma and } \\
\text { pertussis }\end{array}$ & 2917 & 4122 & $0 \cdot 274(0 \cdot 265-0 \cdot 285)$ & $3 \cdot 959(3 \cdot 808-4 \cdot 115)$ \\
\hline $\begin{array}{l}\text { Patients with pre-existing asthma and no } \\
\text { pertussis }\end{array}$ & 3969136 & 10625678 & & \\
\hline $\begin{array}{l}\text { Patients with no pre-existing COPD or } \\
\text { asthma and pertussis }\end{array}$ & 20672 & 48521 & $0.069(0.068-0.070)$ & - \\
\hline $\begin{array}{l}\text { Patients with no pre-existing COPD or } \\
\text { asthma and no pertussis }\end{array}$ & 124228622 & 298178050 & & \\
\hline \multicolumn{5}{|l|}{ Patients aged $11-18$ years } \\
\hline $\begin{array}{l}\text { Patients with pre-existing COPD and } \\
\text { pertussis }\end{array}$ & 89 & 75 & $0.423(0 \cdot 340-0 \cdot 521)$ & $3 \cdot 225(2 \cdot 616-3 \cdot 976)$ \\
\hline $\begin{array}{l}\text { Patients with pre-existing COPD and no } \\
\text { pertussis }\end{array}$ & 63241 & 210259 & & \\
\hline $\begin{array}{l}\text { Patients with pre-existing asthma and } \\
\text { pertussis }\end{array}$ & 1073 & 1389 & $0.410(0 \cdot 385-0.435)$ & $3 \cdot 122(2 \cdot 926-3 \cdot 331)$ \\
\hline $\begin{array}{l}\text { Patients with pre-existing asthma and no } \\
\text { pertussis }\end{array}$ & 866107 & 2618735 & & \\
\hline $\begin{array}{l}\text { Patients with no pre-existing COPD or } \\
\text { asthma and pertussis }\end{array}$ & 6181 & 14972 & $0 \cdot 131(0 \cdot 128-0 \cdot 135)$ & - \\
\hline $\begin{array}{l}\text { Patients with no pre-existing COPD or } \\
\text { asthma and no pertussis }\end{array}$ & 20474781 & 47100219 & & \\
\hline \multicolumn{5}{|l|}{ Patients aged $19-64$ years } \\
\hline $\begin{array}{l}\text { Patients with pre-existing COPD and } \\
\text { pertussis }\end{array}$ & 889 & 1293 & $0 \cdot 206(0 \cdot 193-0 \cdot 220)$ & $3 \cdot 588(3 \cdot 353-3 \cdot 840)$ \\
\hline $\begin{array}{l}\text { Patients with pre-existing COPD and no } \\
\text { pertussis }\end{array}$ & 1515789 & 4316406 & & \\
\hline $\begin{array}{l}\text { Patients with pre-existing asthma and } \\
\text { pertussis }\end{array}$ & 1721 & 2547 & $0 \cdot 233(0 \cdot 222-0 \cdot 244)$ & $4 \cdot 060(3 \cdot 861-4 \cdot 269)$ \\
\hline $\begin{array}{l}\text { Patients with pre-existing asthma and no } \\
\text { pertussis }\end{array}$ & 2863430 & 7384314 & & \\
\hline $\begin{array}{l}\text { Patients with no pre-existing COPD or } \\
\text { asthma and pertussis }\end{array}$ & 13200 & 30392 & $0 \cdot 057(0 \cdot 056-0 \cdot 058)$ & - \\
\hline $\begin{array}{l}\text { Patients with no pre-existing COPD or } \\
\text { asthma and no pertussis }\end{array}$ & 96930843 & 230008831 & & \\
\hline \multicolumn{5}{|l|}{ Patients aged $65+$ years } \\
\hline $\begin{array}{l}\text { Patients with pre-existing COPD and } \\
\text { pertussis }\end{array}$ & 335 & 572 & $0 \cdot 114(0 \cdot 102-0 \cdot 126)$ & $1 \cdot 854(1 \cdot 644-2 \cdot 090)$ \\
\hline $\begin{array}{l}\text { Patients with pre-existing COPD and no } \\
\text { pertussis }\end{array}$ & 1102900 & 2949454 & & \\
\hline $\begin{array}{l}\text { Patients with pre-existing asthma and } \\
\text { pertussis }\end{array}$ & 123 & 187 & $0 \cdot 197(0 \cdot 164-0 \cdot 236)$ & $3 \cdot 224(2 \cdot 679-3 \cdot 878)$ \\
\hline $\begin{array}{l}\text { Patients with pre-existing asthma and no } \\
\text { pertussis }\end{array}$ & 239599 & 622629 & & \\
\hline $\begin{array}{l}\text { Patients with no pre-existing COPD or } \\
\text { asthma and pertussis }\end{array}$ & 1291 & 3158 & $0 \cdot 061(0 \cdot 058-0 \cdot 065)$ & - \\
\hline $\begin{array}{l}\text { Patients with no pre-existing COPD or } \\
\text { asthma and no pertussis }\end{array}$ & 6822998 & 21069001 & & \\
\hline
\end{tabular}

CI, confidence interval; COPD, chronic obstructive pulmonary disease. 
Table 2. Sample characteristics

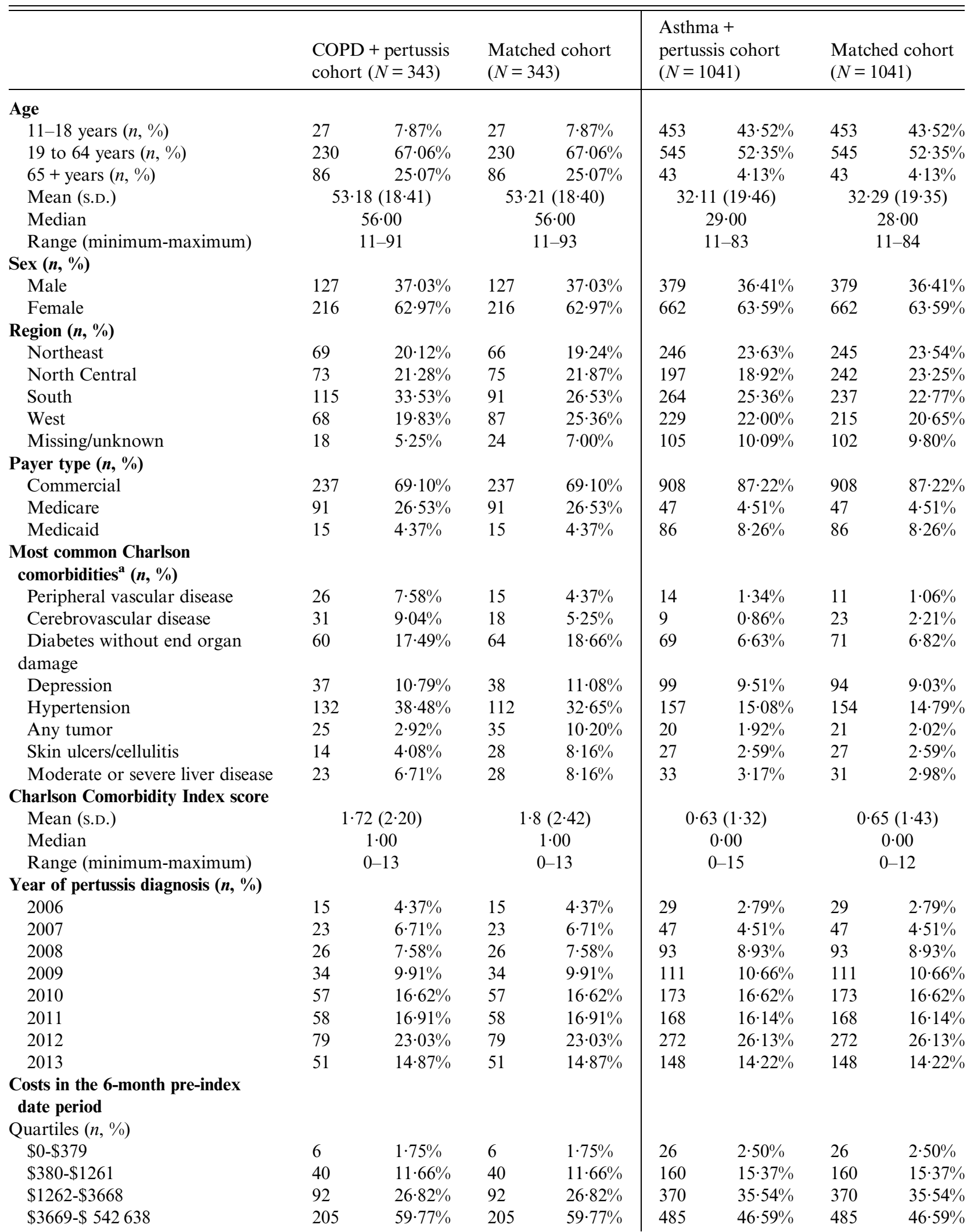


Table 2 (cont.)

\begin{tabular}{lcc|cc}
\hline \hline & $\begin{array}{l}\text { COPD + pertussis } \\
\text { cohort }(N=343)\end{array}$ & $\begin{array}{l}\text { Matched cohort } \\
(N=343)\end{array}$ & $\begin{array}{l}\text { Asthma }+ \\
\text { pertussis cohort } \\
(N=1041)\end{array}$ & $\begin{array}{l}\text { Matched cohort } \\
(N=1041)\end{array}$ \\
\hline Mean (s.D.) & $\$ 12230(\$ 34058)$ & $\$ 10413(\$ 22142)$ & $\$ 7360(\$ 14464)$ & $\$ 6095(\$ 11052)$ \\
Median & $\$ 4805$ & $\$ 4392$ & $\$ 3119$ & $\$ 2958$ \\
Range (minimum-maximum) & $\$ 72-\$ 530969$ & $\$ 78-\$ 241122$ & $\$ 0-\$ 228595$ & $\$ 0-\$ 143295$ \\
\hline \hline
\end{tabular}

COPD, chronic obstructive pulmonary disease; s.D., standard deviation.

${ }^{\text {a }}$ Charlson comorbidities measured in the 6-month pre-study index date period, and excluding COPD. The comorbidities presented affected more than $7 \%$ of any cohort or more than $2 \%$ of all cohorts. The comorbidities not presented included congestive heart failure, myocardial infarction, dementia, connective tissue disease, ulcer disease, use of warfarin, hemiplegia, moderate or severe renal disease, diabetes with end-organ damage, mild liver disease, metastatic cancer, and AIDS.

The mean (S.D.) CCI score was $1.7(2 \cdot 2)$ for the COPD + PERT cohort vs. $1.8(2 \cdot 4)$ for the matched cohort. For both the COPD + PERT cohort and the matched cohort, the highest proportion of pertussis diagnoses occurred in 2012. Mean (S.D.) costs during the 6-month pre-index date period were slightly higher for the COPD + PERT cohort (\$12 230 (\$34 058)) than for the matched cohort (\$10 413 (\$22 142)).

The mean (S.D.) age of the ASTHMA + PERT cohort was $32 \cdot 1(19 \cdot 5)$ years, and approximately two-thirds of this cohort was female. The mean (s.D.) CCI score was $0.6(1.3)$ for patients with preexisting asthma and pertussis vs. $0 \cdot 7(1 \cdot 4)$ for matched patients. For both the ASTHMA + PERT cohort and the matched cohort, the highest proportion of pertussis diagnoses occurred in 2012. Mean (s.D.) costs during the 6-month pre-index date period were slightly higher among the ASTHMA + PERT cohort (\$7360 (\$14464)) than for the matched cohort (\$6095 (\$11 052)).

\section{Hospitalizations}

During the 45 days, 3 months and 6 months post-index date, the difference in the percentage of patients with at least one all-cause hospitalization was greater in the COPD + PERT cohort than in the matched cohort relative to the respective periods pre-index date (Table 3 ). Likewise, during all three post-index date periods, the differences in the percentage of patients with at least one all-cause hospitalization were greater in the ASTHMA + PERT cohort than in the matched cohort relative to the respective periods pre-index date.

Similar patterns were observed for pertussis-related hospitalization patterns: across all three post-index date periods, the percentage of patients with at least one pertussis-related hospitalization were greater in the COPD + PERT and ASTHMA + PERT cohorts than in the respective matched cohorts.

\section{Unadjusted costs}

\section{Unadjusted all-cause costs}

During the 45 days post-index date, the COPD + PERT cohort accrued $\$ 4150$ more than they accrued during the 45 days pre-index date, whereas the matchedcontrol cohort accrued $\$ 1201$ more during the 45 days post-index date, resulting in an excess cost of pertussis in patients with COPD of $\$ 2950(P=0 \cdot 009)$ compared with patients with pertussis without COPD (Table 4). For the 3-month and 6-month periods, the excess costs of pertussis in the COPD + PERT cohort compared with the matched-control cohort were $\$ 3499(P=0 \cdot 026)$ and $\$ 5657(P=0 \cdot 012)$, respectively. During the 45 days post-index date, the ASTHMA + PERT cohort accrued $\$ 1746$ more than they accrued during the 45 days pre-index date, whereas the matchedcontrol cohort accrued $\$ 1084$ more during the 45 days post-index date, resulting in an excess cost of pertussis in patients with asthma compared with patients with pertussis without asthma of $\$ 662(P=0 \cdot 079)$. For the 3 - and 6-month periods, the excess costs of pertussis in the ASTHMA + PERT cohort compared with the matched-control cohort were $\$ 591 \quad(P=0.244)$ and $\$ 1386(P=0 \cdot 129)$, respectively.

\section{Unadjusted pertussis-related costs}

Compared with the matched cohort, the COPD + PERT cohort accrued $\$ 956$ more in pertussis-related unadjusted costs during the 45 days post-index date $(P=0 \cdot 128), \$ 972$ more during the 3 months post-index date $(P=0 \cdot 121)$, and $\$ 979$ more during the 6 months post-index date $(P=0 \cdot 119)$ (Table 4). Compared with the matched 
Table 3. Difference in likelihood of hospitalizations after pertussis diagnosis, by time period and cohort

\begin{tabular}{|c|c|c|c|c|c|c|}
\hline Time period & $\begin{array}{l}\text { COPD + } \\
\text { pertussis cohort } \\
(N=343)\end{array}$ & $\begin{array}{l}\text { Matched cohort } \\
(N=343)\end{array}$ & Difference & $\begin{array}{l}\text { Asthma }+ \\
\text { pertussis cohort } \\
(N=1041)\end{array}$ & $\begin{array}{l}\text { Matched cohort } \\
(N=1041)\end{array}$ & Difference \\
\hline \multicolumn{7}{|c|}{ All-cause $\geqslant 1$ hospital admission $(\%)^{a}$} \\
\hline 45 days & $12 \cdot 24$ & $6 \cdot 41$ & $5 \cdot 83$ & $6 \cdot 92$ & $2 \cdot 60$ & $4 \cdot 32$ \\
\hline 3 months & $10 \cdot 21$ & $5 \cdot 54$ & $4 \cdot 67$ & $5 \cdot 47$ & $2 \cdot 98$ & $2 \cdot 49$ \\
\hline 6 months & $8 \cdot 46$ & $4 \cdot 95$ & $3 \cdot 51$ & $4 \cdot 51$ & 1.92 & $2 \cdot 59$ \\
\hline \multicolumn{7}{|c|}{ Pertussis-related $\geqslant 1$ hospital admission $(\%)^{b}$} \\
\hline 45 days & $4 \cdot 08$ & $2 \cdot 33$ & $1 \cdot 75$ & $2 \cdot 02$ & $1 \cdot 44$ & $0 \cdot 58$ \\
\hline 3 months & $4 \cdot 08$ & $2 \cdot 33$ & $1 \cdot 75$ & $2 \cdot 02$ & $1 \cdot 44$ & $0 \cdot 58$ \\
\hline 6 months & $4 \cdot 08$ & $2 \cdot 33$ & $1 \cdot 75$ & $2 \cdot 02$ & $1 \cdot 44$ & $0 \cdot 58$ \\
\hline
\end{tabular}

COPD, chronic obstructive pulmonary disease.

${ }^{a}$ All-cause hospitalizations reflect the difference in the percentage of patients with $\geqslant 1$ hospitalization during the 45-day, 3-month, and 6-month periods post-pertussis index date, respectively, relative to the 45-day, 3-month, and 6-month periods pre-pertussis index date.

${ }^{\mathrm{b}}$ Pertussis-related hospitalizations reflect the percentage of patients with $\geqslant 1$ hospitalization related to pertussis in the 45 days, 3 months, and 6 months post-pertussis index date.

cohort, the ASTHMA + PERT cohort accrued $\$ 175$ more in pertussis-related unadjusted costs during the 45 days post-index date $(P=0.032), \$ 188$ more during the 3 months post-index date $(P=0.021)$, and $\$ 197$ more during the 6 months post-index date $(P=0.016)$.

\section{Adjusted costs}

\section{Adjusted all-cause costs}

In the 45-day period after the index date, the COPD + PERT cohort accrued $\$ 4751$ in all-cause adjusted health care costs, whereas the matched cohort accrued $\$ 1057$ in all-cause adjusted health care costs. This resulted in $\$ 3694$ more in all-cause adjusted costs associated with the COPD + PERT cohort compared with the matched cohort $(P<0 \cdot 0001)$ (Fig. 1). The difference in all-cause adjusted costs of the COPD + PERT cohort vs. the matched cohort increased to $\$ 4173$ in the 3 months post-index date and to $\$ 6154$ in the 6 months post-index date (both $P<0.0001$ ). The difference in all-cause adjusted costs between the COPD + PERT cohort $v$. the matched cohort was found to increase with age during the 45-day post-index date period ( $\$ 1474$ among patients aged 11-18 years, \$3356 among patients aged 19-64 years, and \$5295 among patients aged $65+$ years; all $P<0.0001)$. The trend of increasing differences in all-cause adjusted costs with increasing patient age continued during the 3-month period (\$1643 among patients aged 11-18 years, \$4092 among patients aged 19-64 years, and \$5184 among patients aged $65+$ years; all $P<0.0001)$ and the 6-month period (\$2276 among patients aged 11-18 years, \$6110 among patients aged 19-64 years, and $\$ 7491$ among patients aged $65+$ years; all $P<0 \cdot 0001$ ).

In the 45-day period after the index date, the ASTHMA + PERT cohort accrued \$2007 in all-cause adjusted health care costs, whereas the matched cohort accrued $\$ 814$ in all-cause adjusted health care costs. This resulted in $\$ 1193$ more in all-cause adjusted costs associated with the ASTHMA + PERT cohort compared with the matched cohort $(P<0 \cdot 0001)$ (Fig. 2). The difference in all-cause adjusted costs between the ASTHMA + PERT cohort $v s$. the matched cohort increased slightly to $\$ 1301$ in the 3 months post-index date and to $\$ 1639$ in the 6 months post-index date (both $P<0.0001$ ). The difference in all-cause adjusted costs between the ASTHMA + PERT cohort $v s$. the matched cohort was found to increase with increasing patient age during the 45-day post-index date period (\$746 among patients aged 11-18 years, \$1460 among patients aged 19-64 years, and \$2510 among patients aged $65+$ years; all $P<0 \cdot 0001)$. The trend of increasing differences in all-cause adjusted costs with increasing patient age continued during the 3-month period (\$794 among patients aged 11-18 years, \$1632 among patients aged 19-64 years, and \$2436 among patients aged $65+$ years; all $P<0.0001$ ) and the 6-month period (\$1021 among patients aged 11-18 years, \$2087 among patients aged 19-64 years, and \$2475 among patients aged $65+$ years; all $P<0 \cdot 0001)$.

\section{Adjusted pertussis-related costs}

The difference in pertussis-related adjusted costs between the COPD + PERT cohort and the matched 
Table 4. Unadjusted mean difference in all-cause and pertussis-related costs, by time period and cohort

\begin{tabular}{|c|c|c|c|c|c|c|}
\hline Time period & $\begin{array}{l}\text { COPD + } \\
\text { pertussis cohort } \\
(N=343)\end{array}$ & $\begin{array}{l}\text { Matched cohort } \\
(N=343)\end{array}$ & $\begin{array}{l}\text { Difference }{ }^{\mathrm{a}} \\
(P \text { value })\end{array}$ & $\begin{array}{l}\text { Asthma }+ \\
\text { pertussis cohort } \\
(N=1041)\end{array}$ & $\begin{array}{l}\text { Matched cohort } \\
(N=1041)\end{array}$ & $\begin{array}{l}\text { Difference }{ }^{\mathrm{a}} \\
(P \text { value })\end{array}$ \\
\hline \multicolumn{7}{|c|}{ All-cause health care costs ${ }^{b}$} \\
\hline \multicolumn{7}{|l|}{45 days } \\
\hline Overall costs & $\$ 4150$ & $\$ 1201$ & $\begin{array}{l}\$ 2950 \\
(P=0 \cdot 009)\end{array}$ & $\$ 1746$ & $\$ 1084$ & $\begin{array}{l}\$ 662 \\
(P=0.079)\end{array}$ \\
\hline Inpatient costs & $\$ 3675$ & $\$ 1147$ & $\$ 2529$ & $\$ 1060$ & $\$ 643$ & $\$ 417$ \\
\hline Outpatient costs & $\$ 461$ & $\$ 93$ & $\$ 368$ & $\$ 614$ & $\$ 365$ & $\$ 249$ \\
\hline Pharmacy costs & $\$ 14$ & $-\$ 39$ & $\$ 53$ & $\$ 72$ & $\$ 76$ & $-\$ 4$ \\
\hline \multicolumn{7}{|l|}{3 months } \\
\hline Overall costs & $\$ 4446$ & $\$ 997$ & $\begin{array}{l}\$ 3449 \\
\quad(P=0 \cdot 026)\end{array}$ & $\$ 1698$ & $\$ 1107$ & $\begin{array}{l}\$ 591 \\
\quad(P=0.244)\end{array}$ \\
\hline Inpatient costs & $\$ 3625$ & $\$ 1350$ & $\$ 2274$ & $\$ 929$ & $\$ 634$ & $\$ 295$ \\
\hline Outpatient costs & $\$ 719$ & $-\$ 60$ & $\$ 781$ & $\$ 640$ & $\$ 449$ & $\$ 191$ \\
\hline Pharmacy costs & $\$ 102$ & $-\$ 293$ & $\$ 394$ & $\$ 129$ & $\$ 24$ & $\$ 105$ \\
\hline \multicolumn{7}{|l|}{6 months } \\
\hline Overall costs & $\$ 5858$ & $\$ 201$ & $\begin{array}{l}\$ 5657 \\
\quad(P=0 \cdot 012)\end{array}$ & $\$ 2687$ & $\$ 1301$ & $\begin{array}{l}\$ 1386 \\
(P=0 \cdot 129)\end{array}$ \\
\hline Inpatient costs & $\$ 4339$ & $\$ 1029$ & $\$ 3310$ & $\$ 1390$ & $\$ 962$ & $\$ 427$ \\
\hline Outpatient costs & $\$ 1393$ & $-\$ 445$ & $\$ 1837$ & $\$ 1075$ & $\$ 317$ & $\$ 759$ \\
\hline Pharmacy costs & $\$ 126$ & $-\$ 383$ & $\$ 510$ & $\$ 222$ & $\$ 22$ & $\$ 200$ \\
\hline \multicolumn{7}{|c|}{ Pertussis-related costs ${ }^{\mathrm{c}}$} \\
\hline \multicolumn{7}{|l|}{45 days } \\
\hline Overall costs & $\$ 1451$ & $\$ 496$ & $\begin{array}{l}\$ 956 \\
\quad(P=0 \cdot 128)\end{array}$ & $\$ 522$ & $\$ 347$ & $\begin{array}{l}\$ 175 \\
\quad(P=0.032)\end{array}$ \\
\hline Inpatient costs & $\$ 1098$ & $\$ 286$ & $\$ 812$ & $\$ 178$ & $\$ 164$ & $\$ 14$ \\
\hline Outpatient costs & $\$ 334$ & $\$ 195$ & $\$ 140$ & $\$ 324$ & $\$ 166$ & $\$ 158$ \\
\hline Pharmacy costs & $\$ 19$ & $\$ 15$ & $\$ 4$ & $\$ 20$ & $\$ 17$ & $\$ 3$ \\
\hline \multicolumn{7}{|l|}{3 months } \\
\hline Overall costs & $\$ 1475$ & $\$ 502$ & $\begin{array}{l}\$ 972 \\
\quad(P=0 \cdot 121)\end{array}$ & $\$ 541$ & $\$ 353$ & $\begin{array}{l}\$ 188 \\
\quad(P=0.021)\end{array}$ \\
\hline Inpatient costs & $\$ 1098$ & $\$ 286$ & $\$ 812$ & $\$ 178$ & $\$ 164$ & $\$ 14$ \\
\hline Outpatient costs & $\$ 354$ & $\$ 200$ & $\$ 153$ & $\$ 339$ & $\$ 170$ & $\$ 168$ \\
\hline Pharmacy costs & $\$ 23$ & $\$ 16$ & $\$ 7$ & $\$ 24$ & $\$ 19$ & $\$ 6$ \\
\hline \multicolumn{7}{|l|}{6 months } \\
\hline Overall costs & $\$ 1487$ & $\$ 509$ & $\begin{array}{l}\$ 979 \\
\quad(P=0 \cdot 119)\end{array}$ & $\$ 555$ & $\$ 358$ & $\begin{array}{l}\$ 197 \\
\quad(P=0.016)\end{array}$ \\
\hline Inpatient costs & $\$ 1098$ & $\$ 286$ & $\$ 812$ & $\$ 178$ & $\$ 164$ & $\$ 14$ \\
\hline Outpatient costs & $\$ 359$ & $\$ 204$ & $\$ 156$ & $\$ 346$ & $\$ 172$ & $\$ 174$ \\
\hline Pharmacy costs & $\$ 30$ & $\$ 19$ & $\$ 11$ & $\$ 31$ & $\$ 22$ & $\$ 9$ \\
\hline
\end{tabular}

COPD, chronic obstructive pulmonary disease.

${ }^{\text {a }}$ Due to rounding, the difference may not correspond to the difference between the individual values presented for the COPD + pertussis cohort and the matched cohort.

${ }^{\mathrm{b}}$ All-cause costs reflect the difference in costs (i.e., all medical and pharmacy costs, regardless of the corresponding diagnoses or prescriptions) incurred during the 45-day, 3-month, and 6-month periods post-pertussis index date (including pertussisrelated costs), respectively, relative to the 45-day, 3-month, and 6-month periods pre-pertussis index date.

${ }^{\mathrm{c}}$ Pertussis-related costs reflect costs associated with pertussis in the 45 days, 3 months, and 6 months post-pertussis index date.

cohort was $\$ 369$ in the 45-day period after the index date, $\$ 435$ during the 3-month period, and $\$ 463$ during the 6-month period (all $P<0 \cdot 0001$ ) (Fig. 3). The difference in pertussis-related adjusted costs between the COPD + PERT cohort vs. the matched cohort during the 45-day period was found to increase with increasing patient age (\$264 among patients aged 11-18 years, \$361 among patients 19-64 years, and $\$ 423$ among patients aged $65+$ years; all $P<0 \cdot 01$ ). The trend of increasing differences in pertussis-related adjusted costs with age continued during the 3-month period (\$281 among patients aged $11-18$ years, $\$ 428$ 


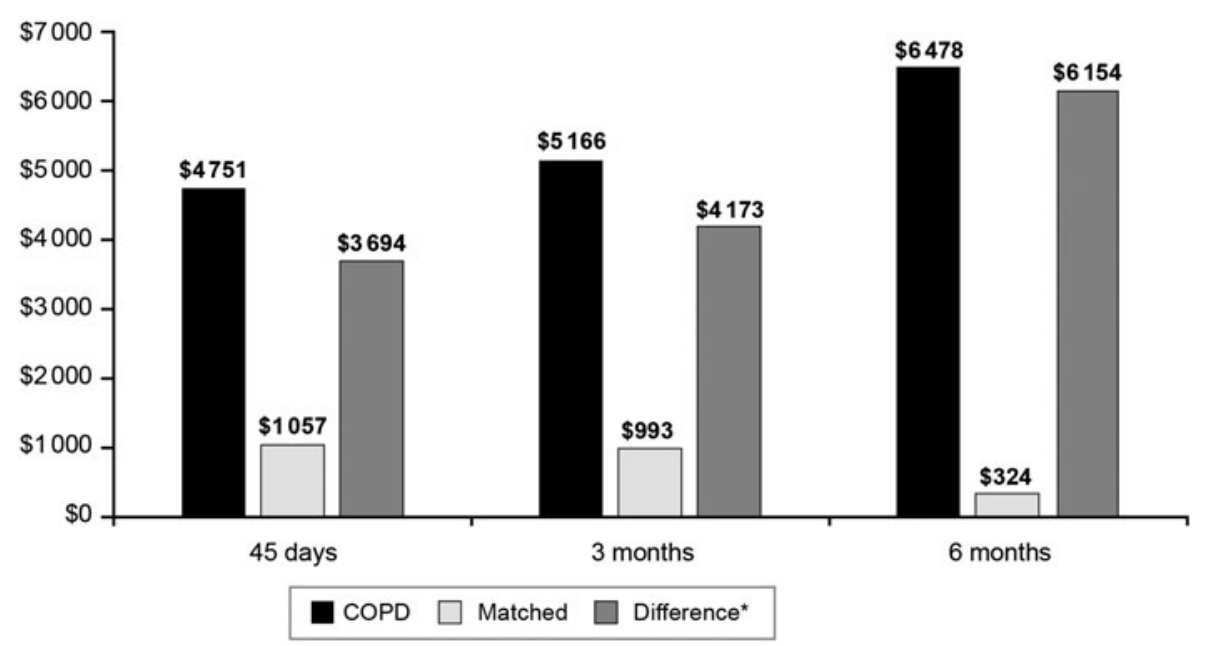

Fig. 1. Adjusted all-cause health care costs for patients with pre-existing COPD and pertussis and matched patients with pertussis only in the 45 days, 3 months, and 6 months following the index date. COPD $=$ chronic obstructive pulmonary disease. ${ }^{*} P<0.0001$ for all differences.

among patients aged 19-64 years, and \$500 among patients aged $65+$ years; all $P<0.01)$ and the 6-month period (\$285 among patients aged 11-18 years, \$459 among patients aged 19-64 years, and $\$ 528$ among patients aged $65+$ years; all $P<0 \cdot 01$ ).

The difference in pertussis-related adjusted costs between the ASTHMA + PERT cohort and the matched cohort was $\$ 230$ in the 45-day period after the index date, $\$ 241$ during the 3-month period, and $\$ 251$ during the 6-month period (all $P<0.0001$ ) (Fig. 4). The differences in pertussis-related adjusted costs between the ASTHMA + PERT cohort vs. the matched cohort were similar across age groups during the 45-day period ( $\$ 183$ among patients aged 11-18 years, \$267 among patients aged 19-64 years, and $\$ 255$ among patients aged $65+$ years; all $P<$ $0.0001)$. Similar differences in pertussis-related adjusted costs between the ASTHMA + PERT cohort $v s$. the matched cohort were also observed across age groups during the 3-month period (\$193 among patients aged 11-18 years, \$278 among patients aged 19-64 years, and \$266 among patients aged $65+$ years; all $P<0.0001$ ) and during the 6-month period (\$204 among patients aged 11-18 years, \$289 among patients aged 19-64 years, and \$276 among patients aged $65+$ years; all $P<0 \cdot 0001$ ).

\section{DISCUSSION}

This retrospective database analysis compared patients with diagnosed pertussis and pre-existing asthma or COPD with matched patients who had diagnosed pertussis but no pre-existing asthma or
COPD, and reported on the incidence of diagnosed pertussis as well as all-cause and pertussis-related costs. The results for the 2006-2014 study period may be generalizable to a large insured US population. The observed incidence rates varied considerably across age groups, with the highest incidence occurring among adolescents aged 11-18 years in both the PERT + COPD and the PERT + ASTHMA populations. Similar variations in incidence by age have been reported by the CDC during this time frame [18], but, to our knowledge, there is limited evidence on the incidence of pertussis among individuals with pre-existing asthma or COPD.

Respiratory infections such as pertussis are associated with an increase in acute exacerbations in patients with asthma and COPD [19-22]. Furthermore, some research has suggested that patients with asthma or COPD may be at increased risk for pertussis compared with patients without either of these conditions [5, 7, 8, 9]. Our study builds upon the current literature and shows that, regardless of the age group, the incidence of ICD-9-CM-diagnosed pertussis was higher among patients with a diagnosis of COPD or asthma compared with patients without either of these conditions.

Additionally, limited published data exist regarding costs associated with pertussis in adolescents and adults. A small US survey study evaluating the economic impact of pertussis among adolescents found societal costs, including direct medical and indirect costs, to be in excess of $\$ 315$ per affected household [23]. Further, a study by McGuiness and colleagues [6] evaluated US patients with pertussis aged 50 years and older and reported on inpatient and 


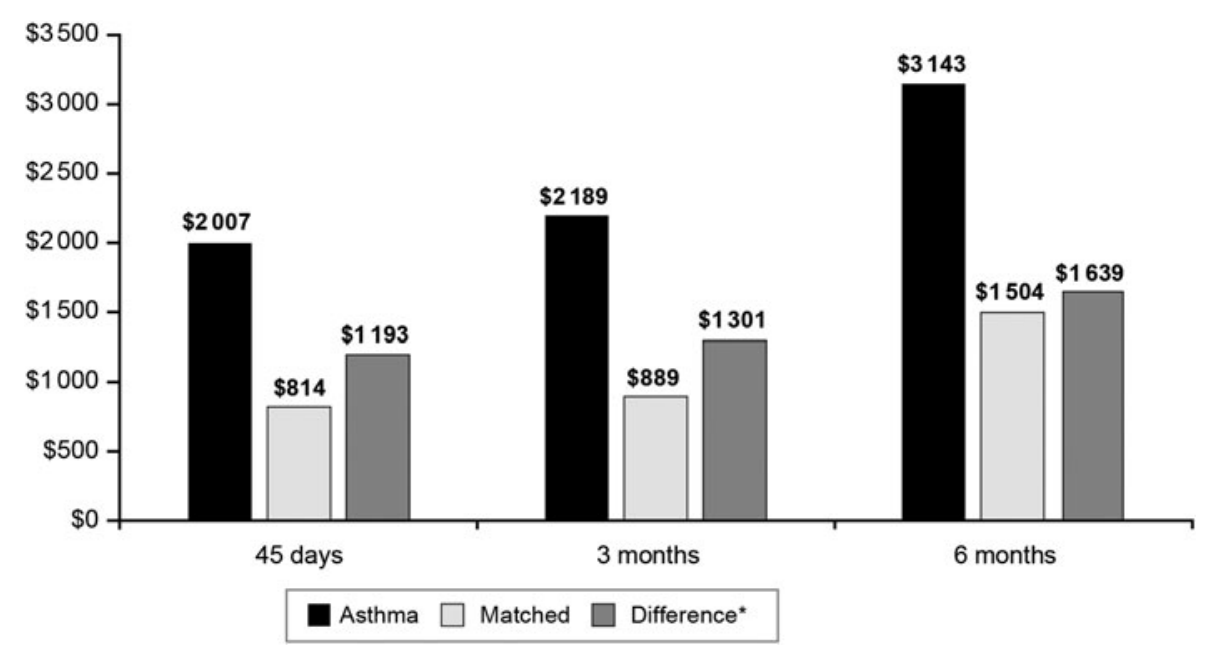

Fig. 2. Adjusted all-cause health care costs for patients with pre-existing asthma and pertussis and matched patients with pertussis only in the 45 days, 3 months, and 6 months following the index date. ${ }^{*} P<0 \cdot 0001$ for all differences.

outpatient health care costs using a retrospective database. Their study found that patients with pertussis accrued between $\$ 1835$ and $\$ 14428$ in all-cause costs, depending on whether they received treatment in the inpatient or outpatient setting. Results from this study are not directly comparable with our analysis, which included adolescents and adults of all ages and stratified patients with pertussis by COPD and asthma status. Nevertheless, average adjusted perpatient all-cause costs in our analysis were within the range of all-cause costs identified by McGuiness and colleagues [6], ranging from $\$ 3143$ for patients with asthma to $\$ 6478$ for patients with COPD in the 6 months post-index date.

Our study supports previous findings that pertussis may be associated with worsening COPD and asthma symptoms, thereby increasing the overall economic burden of the diseases. Among patients with preexisting COPD in particular, all-cause costs increased with time following a diagnosis of pertussis, whereas all-cause costs decreased over time for matched patients without COPD. These findings suggest that patients with pre-existing COPD can experience negative consequences from pertussis for at least 6 months. Specifically, matched patients without COPD accrued $\$ 1057$ in adjusted costs (while controlling for costs in the pre-index date period) in the 45 days after the index date. However, adjusted costs for matched patients without COPD were found to decrease over time, with matched patients without COPD having just $\$ 324$ in adjusted costs in the 6 months after the index date. This indicates that patients without COPD did not experience lingering symptoms and that the pertussis diagnosis did not have long-term health consequences for patients without pre-existing asthma or COPD. Contrasting this with patients with COPD, the burden of pertussis increased over time even after controlling for baseline health care costs, from adjusted costs of $\$ 4751$ in the 45 -day postindex date to $\$ 6478$ in the 6-month post-index date, indicating that patients with pertussis and COPD experienced longer term negative consequences from pertussis compared to patients with pertussis without COPD. This conclusion is further supported by the fact that pertussis-related spending remained constant between the 45-day and 6-month period for patients with COPD (i.e., adjusted pertussis-related costs of $\$ 1083$ in the 45-day period and $\$ 1158$ in the 6-month period). Thus, patients were not accruing additional pertussis-related care after the 45-day postindex date period, and all subsequent health care expenditures causing the increase in adjusted all-cause costs over time were not directly related to the treatment of pertussis but rather were associated with increased health care costs due to other concomitant conditions. Similar findings were also observed for asthma patients with pertussis; however, the economic consequences were not as large (range: adjusted allcause costs of \$2007 in the 45-day post-study index period to adjusted all-cause costs of $\$ 3143$ in the 6-month post-study index period).

Tetanus, diphtheria, and acellular pertussis (Tdap) vaccination remains the most effective strategy against infection and in reducing disease severity among adolescents and adults. Protective benefits of Tdap vaccination have ranged from an estimated effectiveness of 


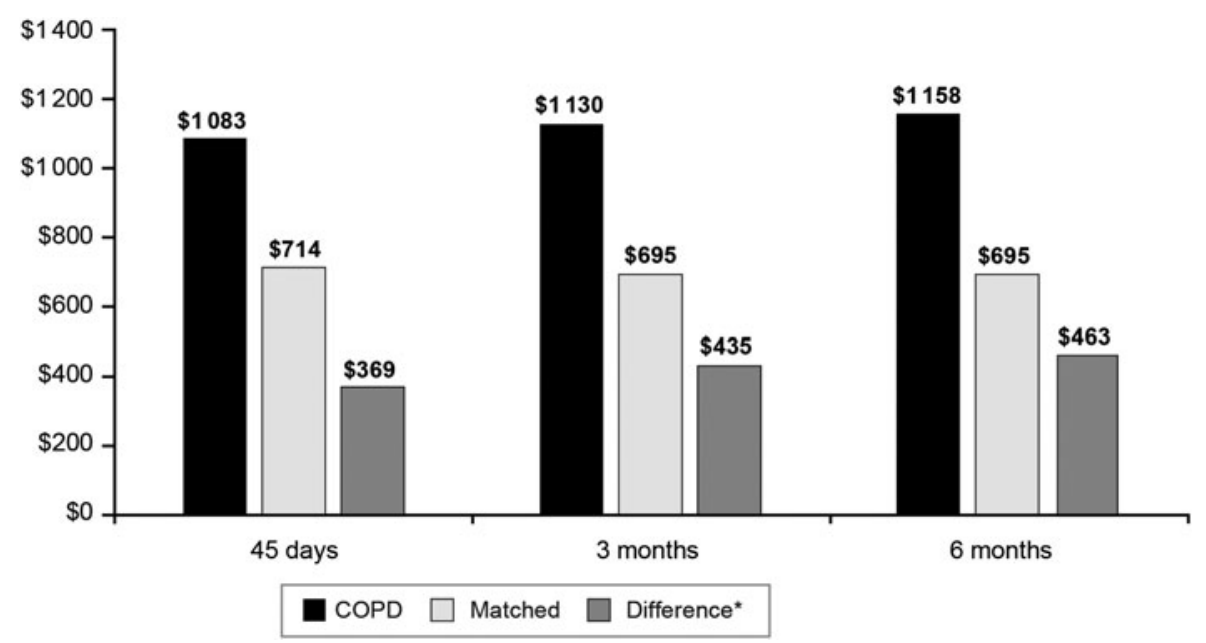

Fig. 3. Adjusted pertussis-related health care costs for patients with pre-existing COPD and pertussis and matched patients with pertussis only in the 45 days, 3 months, and 6 months following the index date. COPD $=$ chronic obstructive pulmonary disease. ${ }^{*} P<0.0001$ for all differences.

$53.0 \%$ among patients aged 11 years or older in the community setting [24] to an estimated efficacy of $92 \%$ among adults participating in the Adult Pertussis Trial [25]; however, recent research has found that this protection from pertussis wanes over time $[26,27]$. Although there are no studies specifically examining Tdap vaccine efficacy among patients with COPD or asthma, whole-cell pertussis vaccination has been shown to have a protective effect against allergic asthma exacerbations [28]. In addition, other vaccines, such as the influenza vaccine, are associated with a reduction in acute exacerbations among patients with COPD [29]. Therefore, incorporating compliance with the Advisory Committee on Immunization Practice (ACIP) Tdap recommendations into COPD and asthma management plans may aid in reducing morbidity and mortality among these patients. The ACIP currently recommends one dose of Tdap vaccine for non-pregnant adolescents (preferred at ages 11 or 12 years) and adults [30]. However, compliance in the general adult population is low; in 2014, an estimated $20 \cdot 1 \%$ of adults had received the Tdap vaccine in the previous 9 years [31]. Given the lack of information on the effectiveness of Tdap in patients with COPD and asthma, further research on the measurable effect of vaccination on infection and disease severity is warranted.

This study has several limitations common to retrospective database analyses, including the potential for coding errors in the administrative claims data and for selection bias. In particular, some of the 27 adolescent patients (aged 11-18 years) in the study sample who had COPD may have been subject to diagnostic coding errors. Although observable measures were used to alleviate the effect of selection bias by conducting direct covariate matching, unmeasured or unknown factors may have affected the outcome differently. Moreover, data on laboratory-confirmed pertussis are unavailable in the MarketScan databases; therefore, pertussis cases were identified using diagnosis codes, which likely resulted in an underestimation of the number of patients with pertussis, especially in adults. Similarly, spirometry testing results were not available, and identification of COPD and asthma also relied on established claims-based algorithms. Additionally, this analysis may have underestimated the incidence and burden of pertussis, as some patients may not have sought care with a health care provider. Finally, some non-pertussis-related illnesses were included when calculating all-cause costs (although because the analysis evaluated the change in costs between the preand post-index date periods, any non-pertussis-related costs that occurred in the post-index period would reasonably have been expected to be balanced out by those in the pre-index date period).

To conclude, this study identified the potential for long-term complications from pertussis among patients with pre-existing respiratory conditions. Additional explorations of disease course and specific outcomes following pertussis infection, including complications and resource-use patterns, in individuals with respiratory comorbidities are warranted. During the 6-month follow-up window after a diagnosis of pertussis, patients with pertussis and COPD accrued approximately $\$ 6154$ more in adjusted health care costs compared with matched patients with pertussis 


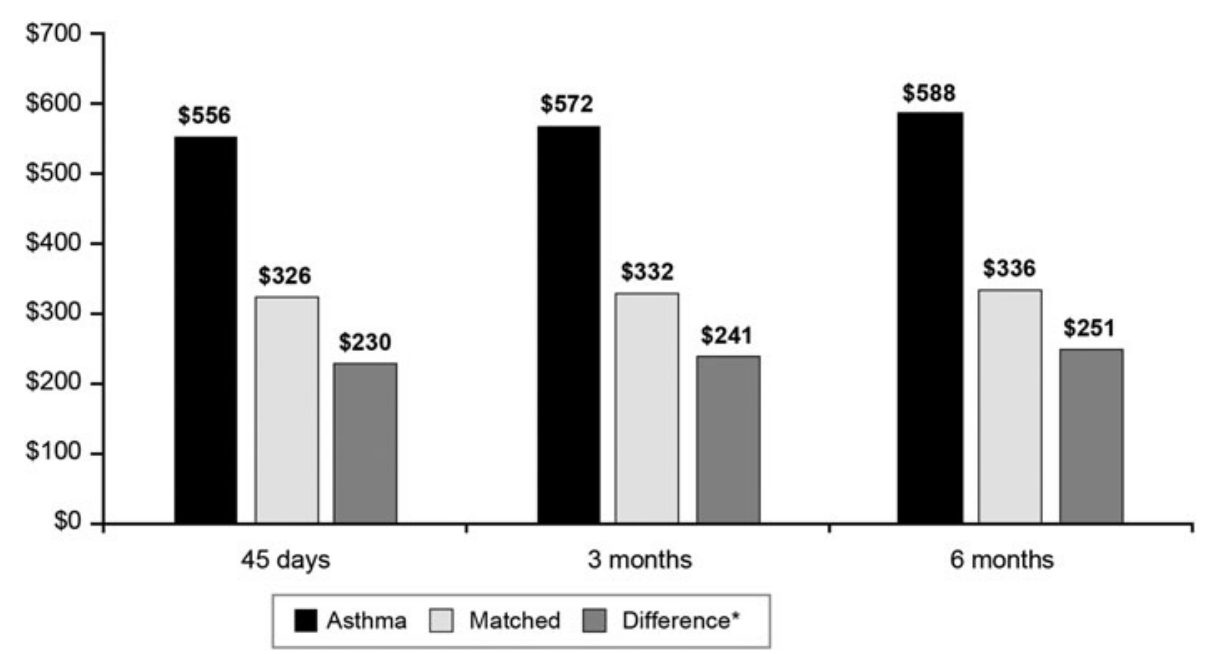

Fig. 4. Adjusted pertussis-related health care costs for patients with pre-existing asthma and pertussis and matched patients with pertussis only in the 45 days, 3 months, and 6 months following the index date. ${ }^{*} P<0 \cdot 0001$ for all differences.

without COPD or asthma, while patients with pertussis and asthma accrued approximately $\$ 1639$ more in adjusted health care costs compared with matched patients with pertussis without COPD or asthma. Additionally, this study found that patients with preexisting asthma or COPD were more likely to have diagnosed pertussis compared with patients without pre-existing asthma or COPD. Focused interventions to prevent pertussis infection among these high-risk patients, including targeted Tdap vaccination strategies, could aid in reducing exacerbation of asthma and COPD, resulting in long-term health care savings.

\section{AUTHOR CONTRIBUTION}

All authors participated in the design, implementation, or analysis of the study and in the interpretation of the study. All authors had full access to the data, contributed to the development of this manuscript, and gave final approval before submission.

\section{ACKNOWLEDGEMENTS}

The authors acknowledge Mayank Ajmera (RTI Health Solutions) for assistance with the preliminary analysis of the study data and Kate Lothman (RTI Health Solutions) for medical writing support. The authors would like to thank Business \& Decision Life Sciences platform for editorial assistance and manuscript coordination, on behalf of GSK Vaccines. Marie Cloes coordinated manuscript development and provided editorial support. GlaxoSmithKline Biologicals SA funded this study (GSK study identifier: HO-15-15543) and was involved in all stages of study conduct, including analysis of the data. GlaxoSmithKline Biologicals SA also took in charge all costs associated with the development and publication of this manuscript.

\section{DECLARATION OF INTEREST}

P.O.B. and L.-D.G. are employees of the GSK group of companies. P.O.B. owns shares in the GSK group of companies as part of his employee remuneration. J.L.M., R.P., S.K.K., and K.L.D. are employees of RTI Health Solutions, which received funding from the GSK group of companies for the conduct of the study. S.K.K. has received contract research funding from Eli Lilly, Pfizer Inc., and LEO Pharma, and K.L.D. has received contract research funding from Merck through their institution.

\section{REFERENCES}

1. Centers for Disease Control and Prevention (CDC). Epidemiology and Prevention of Vaccine-Preventable Diseases. Atkinson W, Wolfe S, Hamborsky J, eds, 12th edn., second printing. Washington, DC: Public Health Foundation, 2012.

2. Adams DA, et al. Summary of notifiable diseases United States, 2012. MMWR: Morbidity and Mortality Weekly Report 2014; 61: 1-121.

3. Centers for Disease Control and Prevention (CDC). 2012 Final Pertussis Surveillance Report, 2013 (https://www. cdc.gov/pertussis/downloads/pertuss-surv-report-2012. pdf). Accessed 12 September 2016.

4. Long SS. Age-specific presentation and burden of pertussis. Advanced Studies in Medicine 2005; 5: S444 S449. 
5. De Serres G, et al. Morbidity of pertussis in adolescents and adults. Journal of Infectious Diseases 2000; 182: 174-179.

6. McGuiness CB, et al. The disease burden of pertussis in adults 50 years old and older in the United States: a retrospective study. BMC Infectious Diseases 2013; 13: 32.

7. Capili CR, et al. Increased risk of pertussis in patients with asthma. Journal of Allergy and Clinical Immunology 2012; 129: 957-963.

8. Liu BC, et al. Pertussis in older adults: prospective study of risk factors and morbidity. Clinical Infectious Diseases 2012; 55: 1450-1456.

9. Hashemi SH, et al. High seroprevalence of Bordetella pertussis in patients with chronic obstructive pulmonary disease: a case-control study. Tanaffos 2015; 14: 172176.

10. Mapel DW, et al. Identifying and characterizing COPD patients in US managed care: a retrospective, crosssectional analysis of administrative claims data. $B M C$ Health Services Research 2011; 11: 43.

11. Gershon AS, et al. Identifying individuals with physician diagnosed COPD in health administrative databases. COPD 2009; 6: 388-394.

12. Ajmera M, et al. Explaining the increased health care expenditures associated with gastroesophageal reflux disease among elderly Medicare beneficiaries with chronic obstructive pulmonary disease: a costdecomposition analysis. International Journal of Chronic Obstructive Pulmonary Disease 2014; 9: 339348.

13. Yang CL, et al. Verifying a questionnaire diagnosis of asthma in children using health claims data. $B M C$ Pulmonary Medicine 2011; 11: 52.

14. Dombkowski KJ, Wasilevich EA, Lyon-Callo SK. Pediatric asthma surveillance using Medicaid claims. Public Health Reports 2005; 120: 515-524.

15. Bureau of Labor Statistics, United States Department of Labor. Medical care component of Consumer Price Index - all urban consumers (current series ID: CUUR0000SAM), not seasonally adjusted, 2016 (http://data.bls.gov/timeseries/cuur0000SAM). Accessed 30 March 2016.

16. Buchan I. Calculating Poisson confidence intervals in Excel, 2004 (http://www.nwph.net/Method_Docs/User \%20Guide.pdf). Accessed 12 September 2016.

17. Ulm K. A simple method to calculate the confidence interval of a standardized mortality ratio (SMR). American Journal of Epidemiology 1990; 131: 373-375.

18. Centers for Disease Control and Prevention (CDC). Reported pertussis incidence by age group: 1990-2014 (http://www.cdc.gov/pertussis/images/incidence-graphage.jpg). Accessed 15 June 2016.

19. Kumar K, Grayson MH. The role of viruses in the development and exacerbation of atopic disease. Annals of Allergy, Asthma, and Immunology 2009; 103: 181-186.

20. Nicholson KG, Kent J, Ireland DC. Respiratory viruses and exacerbations of asthma in adults. BMJ 1993; 307: 982-986.

21. Atmar RL, et al. Respiratory tract viral infections in inner-city asthmatic adults. Archives of Internal Medicine 1998; 158: 2453-2459.

22. De Serres G, et al. Importance of viral and bacterial infections in chronic obstructive pulmonary disease exacerbations. Journal of Clinical Virology 2009; 46: $129-133$

23. Varan AK, et al. Economic and social impact of pertussis among adolescents in San Diego County. Journal of Adolescent Health 2016; 58: 241-244.

24. Baxter R, et al. Effectiveness of pertussis vaccines for adolescents and adults: case-control study. BMJ 2013; 347: f4249.

25. Ward JI, et al. Efficacy of an acellular pertussis vaccine among adolescents and adults. New England Journal of Medicine 2005; 353: 1555-1563.

26. Acosta AM, et al. Tdap vaccine effectiveness in adolescents during the 2012 Washington State pertussis epidemic. Pediatrics 2015; 135: 981-989.

27. Koepke R, et al. Estimating the effectiveness of tetanus-diphtheria-acellular pertussis vaccine (Tdap) for preventing pertussis: evidence of rapidly waning immunity and difference in effectiveness by Tdap brand. Journal of Infectious Diseases 2014; 210: 942 953.

28. Ennis DP, Cassidy JP, Mahon BP. Whole-cell pertussis vaccine protects against Bordetella pertussis exacerbation of allergic asthma. Immunology Letters 2005; 97: 91-100.

29. Varkey JB, Varkey AB, Varkey B. Prophylactic vaccinations in chronic obstructive pulmonary disease: current status. Current Opinion in Pulmonary Medicine 2009; 15: 90-99.

30. Centers for Disease Control and Prevention (CDC). Updated recommendations for use of tetanus toxoid, reduced diphtheria toxoid, and acellular pertussis (Tdap) vaccine in adults aged 65 years and older Advisory Committee on Immunization Practices (ACIP), 2012. MMWR: Morbidity and Mortality Weekly Report 2012; 61: 468-470.

31. Williams WW, et al. Surveillance of vaccination coverage among adult populations - United States, 2014. MMWR: Surveillance Summaries 2016; 65: 1-36. 